\title{
The state of cost-utility analysis in India: A systematic review
}

\author{
Tanu Khurana ${ }^{1}$, Amit Gupta ${ }^{1}$, Hemant Rathi ${ }^{1,2}$
}

${ }^{1}$ Health Economics and Outcomes Research, Skyward Analytics Private Limited, Gurgaon, Haryana, India, ${ }^{2}$ Health Economics and Outcomes Research, Skyward Analytics Pvt. Limited Singapore, Singapore

\begin{abstract}
Aims: Cost-utility studies are crucial tools that help policy-makers promote appropriate resource allocation. The objective of this study was to evaluate the extent and quality of cost-utility analysis (CUA) in India through a systematic literature review.

Methods: Comprehensive database search was conducted to identify the relevant literature published from November 2009 to November 2019. Gray literature and hand searches were also performed. Two researchers independently reviewed and assessed study quality using Consolidated Health Economic Evaluation Reporting Standards checklist.

Results: Thirty-five studies were included in the final review. Thirteen studies used Markov model, five used decision tree model, four used a combination of decision tree and Markov model and one each used microsimulation and dynamic compartmental model. The primary therapeutic areas targeted in CUA were infectious diseases $(n=12)$, ophthalmology $(n=5)$, and endocrine disorders $(n=4)$. Five studies were carried out in Tamil Nadu, four in Goa, three in Punjab, two each in Delhi, Maharashtra, and Uttar Pradesh, and one each in West Bengal and Karnataka. Twenty-three, eight, and four studies were found to be of excellent, very good, and good quality, respectively. The average quality score of the studies was 19.21 out of 24.

Conclusions: This systematic literature review identified the published CUA studies in India. The overall quality of the included studies was good; however, features such as subgroup analyses and explicit study perspective were missing in several evaluations.

Keywords: Consolidated Health Economic Evaluation Reporting Standards checklist, cost-effectiveness, cost-utility, economic evaluation, India, systematic literature review
\end{abstract}

Address for correspondence: Mr. Hemant Rathi, Skyward Analytics Private Limited, Level 18, DLF Cyber City, Building No. 5, Tower A,

Gurgaon - 122 002, Haryana, India.

E-mail: hemant.rathi@skywardanalytics.com

Received: 05-08-20 Revised: 18-11-20 Accepted: 02-12-20 Published: 12-07-21.

\section{INTRODUCTION}

There is increasing pressure on the health-care budget due to the rising costs of health care worldwide. Countries such as the UK and Australia have developed a formal health technology assessment (HTA) system to evaluate the drugs and devices for effectiveness, safety, and value for money. It

\begin{tabular}{|l|l|}
\hline \multicolumn{2}{|c|}{ Access this article online } \\
\hline Quick Response Code: & Website: \\
\hline & www.picronline.org \\
\cline { 2 - 2 } & \\
\hline
\end{tabular}

is undertaken by specialized agencies such as the National Institute for Health and Clinical Excellence ${ }^{[1]}$ in the UK and Pharmaceutical Benefits Advisory Committee ${ }^{[2]}$ in Australia. In these countries, cost consideration in medical decision-making has long been in place. The government decides on drug reimbursements based on the HTA agencies recommendations.

\footnotetext{
This is an open access journal, and articles are distributed under the terms of the Creative Commons Attribution-NonCommercial-ShareAlike 4.0 License, which allows others to remix, tweak, and build upon the work non-commercially, as long as appropriate credit is given and the new creations are licensed under the identical terms.

For reprints contact:WKHLRPMedknow_reprints@wolterskluwer.com
}

How to cite this article: Khurana T, Gupta A, Rathi $\mathrm{H}$. The state of cost-utility analysis in India: A systematic review. Perspect Clin Res 2021;12:179-83. 
In India, Ayushman Bharat scheme was introduced in 2018 to address health-care needs at primary, secondary, and tertiary levels. ${ }^{[3]}$ Such schemes necessitate rationalization of health-care resource use. Cost-utility analysis (CUA) demonstrates the relationship between the cost and benefits of an intervention compared with another intervention and is a useful tool for efficient resource allocation.

The Indian Government has created an institutional setup, HTA in India (HTAIn), under the Department of Health Research to facilitate transparency in the process and evidence-informed decision-making in the field of health. ${ }^{[4]}$

A systematic review of pharmacoeconomic studies from India found that 29 articles focused on drugs were published from 1998 to 2012. ${ }^{[5]}$ Another systematic review retrieved 104 records that were published from 1980 to 2014. ${ }^{\left[{ }^{[}\right]}$However, no study assessed the extent and quality of CUA of health-care interventions and programs in India. The present study, therefore, aims to fulfil the following objectives:

a. To describe the frequency and trends in the publication of cost-utility studies, focusing on health-care interventions and services in India

b. To examine the quality of published cost-utility studies, taking into consideration key methodological issues.

\section{METHODS}

\section{Literature search}

A systematic literature review was performed using a strategy that combined search terms pertaining to economic evaluations. Following databases were searched for the English language publications - PubMed, National Health Service Economic Evaluation Database, and Cochrane library (Search period: November 2009-November 2019). In addition, gray literature and hand searches were performed to identify the relevant articles. The three conferences, Congresses of International Society for Pharmacoeconomics and Outcomes Research (US, Europe, and Asia-Pacific), HTA International, and Society for Medical Decision-Making were searched for relevant articles in the last 2 years. Bibliographic searches of identified studies were also performed.

\section{Study selection}

Studies were selected based on the screening and selection process detailed in Figure 1. Two reviewers independently screened titles and abstracts based on the criteria mentioned below:

Inclusion criteria

- Economic evaluations

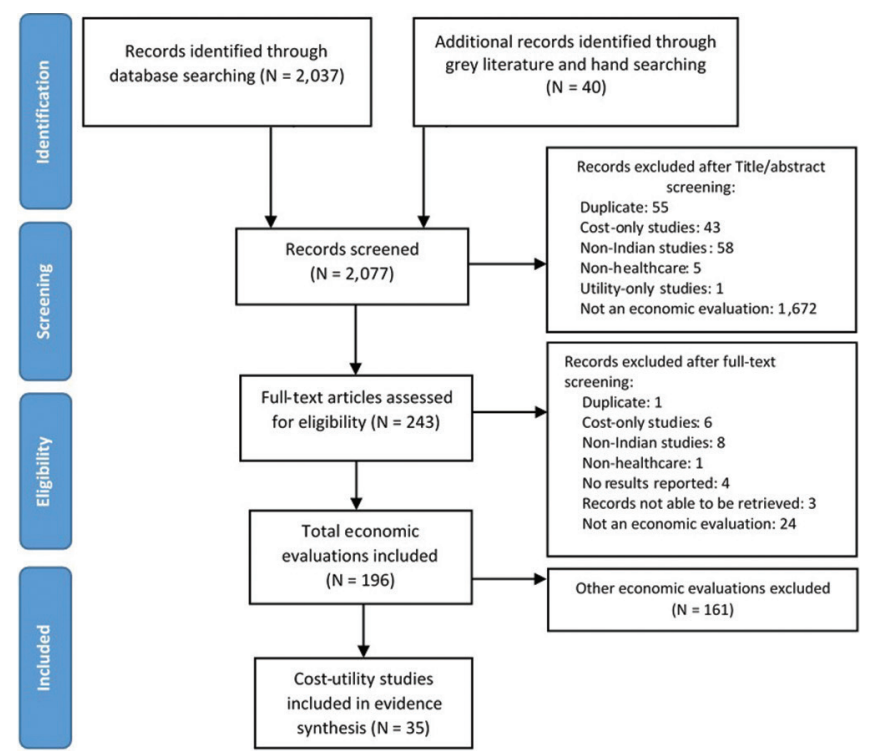

Figure 1: Selection of cost-utility studies for systematic review (original)

- Country: India

- Health-care interventions: pharmaceuticals, medical devices, diagnosis and screening, education programs, and service delivery.

Exclusion criteria

- Duplicate

- In vitro studies

- Cost-only studies

- Utility-only studies

- Non-healthcare interventions

- Non-Indian studies

- Studies with no results or outcomes reported.

Full texts of all the articles included in the above steps were screened based on all the above criteria by two independent reviewers. Disagreement in the screening steps was resolved by a third reviewer.

\section{Data extraction and quality assessment}

A standard data extraction form was developed in Microsoft Excel. One reviewer extracted the data and another performed the quality check.

Quality appraisal of the included studies was performed using the Consolidated Health Economic Evaluation Reporting Standards (CHEERS) checklist, ${ }^{[7]}$ a 24-item checklist to assess the quality of economic evaluations. A score of $0,0.5$, or 1 was allocated for each item on the checklist as follows:

i. 0 : criterion not met

ii. 0.5 : criterion partially met

iii. 1: criterion fully met. 
Total score was calculated out of 24 , and then, a percentage score of each study was calculated. The two reviewers discussed any disagreements in the scoring criteria of the studies, and discordances were resolved by a third reviewer.

\section{RESULTS}

Search results

Database searching $(n=2,037)$ and gray literature and hand searching $(n=40)$ retrieved 2077 articles in total. After screening of the titles and abstracts, 243 studies were shortlisted for full-text screening. A total of 196 articles were found to be economic evaluations, of which 35 were $\mathrm{CUA}^{[8-42]}$ and therefore eligible for this review [Figure 1].

Study characteristics

General characteristics of included studies are briefed in Table 1.

\section{Quality assessment}

In the absence of a widely accepted method of reporting quality assessment, categories were decided based on the methods from published literature. ${ }^{[43]}$ A study was rated excellent if it scored $\geq 85 \%$, very good if it scored between $70 \%$ and $85 \%$, good if the score ranged between $55 \%-70 \%$, and poor if the score was $<55 \%$.

Majority of the studies, $65.71 \%(n=23)$, were of excellent quality, $22.86 \%(n=8)$ and $11.43 \%(n=4)$ studies were of very good and good quality, respectively. None of the studies scored $<55 \%$. Decision model-based studies had better quality scores than non-model (trial, observational) based evaluations (mean 19.97 [85.70\%] vs. 17.55 [81.86]). This may be because these studies clearly defined parameters such as time horizon, discounting, model choice, choice of assumptions, and uncertainty analysis.

The criteria that were the least well addressed in the studies were analytical methods and the choice of the model employed in the studies. Twenty-seven studies did not comprehensively describe the analytical methods supporting their evaluation. Most of the studies, $71.43 \%(n=25)$, did not perform subgroup analysis and hence item 21 on the CHEERS checklist, on characterizing heterogeneity, was not applicable. Other key areas where studies lost points were study perspective (not reported by eight studies), choice of discount rate for costs and outcomes (not reported by 12 studies), and relevance of health outcomes for the type of analysis performed (not reported by 10 studies).
Table 1: Characteristics of cost-utility studies in India $(n=35)$

\begin{tabular}{|c|c|c|}
\hline Characteristic & Category & $n(\%)$ \\
\hline \multirow[t]{2}{*}{ Publication year } & 2009-2014 & $7(20)$ \\
\hline & 2015-2019 & $28(80)$ \\
\hline Lead author's & Foreign & $18(51.43)$ \\
\hline institution affiliation & Indian & $17(48.57)$ \\
\hline \multirow[t]{3}{*}{ Study design } & Model & $24(68.57)$ \\
\hline & Trial based & $9(25.71)$ \\
\hline & Observational & $2(5.71)$ \\
\hline \multirow[t]{6}{*}{ Time horizon (years) } & $<1$ & $1(2.86)$ \\
\hline & $1-5$ & $8(22.86)$ \\
\hline & $5-10$ & $1(2.86)$ \\
\hline & $\geq 10$ but not lifetime & $6(17.14)$ \\
\hline & Lifetime & $14(40)$ \\
\hline & Not reported & $5(14.29)$ \\
\hline \multirow[t]{5}{*}{ Study perspective } & Societal only & $13(37.14)$ \\
\hline & Payer only & $9(25.71)$ \\
\hline & Both payer and societal & $5(14.29)$ \\
\hline & Patient & $1(2.86)$ \\
\hline & Not reported & $7(20)$ \\
\hline \multirow[t]{5}{*}{ Discount rate (\%) } & 3 & $18(51.43)$ \\
\hline & 5 & $1(2.86)$ \\
\hline & 10 & $1(2.86)$ \\
\hline & Not applied & $3(8.57)$ \\
\hline & Not reported & $12(34.29)$ \\
\hline \multirow[t]{6}{*}{ Type of model } & Markov model & $13(37.14)$ \\
\hline & Decision tree & $5(14.29)$ \\
\hline & $\begin{array}{l}\text { Combination of decision tree and } \\
\text { Markov model }\end{array}$ & $4(11.43)$ \\
\hline & Microsimulation model & $1(2.86)$ \\
\hline & Dynamic compartmental model & $1(2.86)$ \\
\hline & Not applicable & $11(31.43)$ \\
\hline \multirow[t]{10}{*}{ States } & Tamil Nadu only & $3(8.57)$ \\
\hline & Tamil Nadu and Delhi & $1(2.86)$ \\
\hline & Tamil Nadu and Maharashtra & $1(2.86)$ \\
\hline & Goa only & $4(11.43)$ \\
\hline & Punjab only & $3(8.57)$ \\
\hline & Delhi only & $1(2.86)$ \\
\hline & Maharashtra only & $1(2.86)$ \\
\hline & Uttar Pradesh only & $2(5.71)$ \\
\hline & West Bengal only & $1(2.86)$ \\
\hline & Not reported & $18(51.43)$ \\
\hline \multirow[t]{7}{*}{ Intervention type } & Drug/vaccine & $14(40)$ \\
\hline & Diagnosis and screening & $7(20)$ \\
\hline & Education program & $6(17.14)$ \\
\hline & Medical device & $3(8.57)$ \\
\hline & Service delivery & $2(5.71)$ \\
\hline & Surgery & 2 (5.71) \\
\hline & Public health program & $1(2.86)$ \\
\hline \multirow[t]{5}{*}{ Therapeutic area } & Infectious diseases & $12(34.3)$ \\
\hline & Ophthalmology & $5(14.3)$ \\
\hline & Endocrine disorders & $4(11.4)$ \\
\hline & Oncology & $3(8.6)$ \\
\hline & Others & 11 (31.4) \\
\hline \multirow[t]{2}{*}{ Sensitivity analysis } & Yes & $29(82.86)$ \\
\hline & No & 6 (17.14) \\
\hline
\end{tabular}

\section{DISCUSSION}

Our review yielded 35 cost-utility studies ${ }^{[8-42]}$ published from November 2009 to November 2019. A region-wise distribution of the studies was almost equal in Northern, Western, and Southern Indian regions, with seven studies conducted in the Northern region, followed by six studies each in the Western and Southern regions. Only one study 
was conducted in the Eastern region. The increase in CUA over last few years reflect the increased interest to understand the costs of healthcare interventions relative to benefits.

The systematic literature review performed by Prinja et al. ${ }^{[6]}$ identified 30 CUA studies published between 1980 and 2014. However, our search retrieved 35 cost-utility studies from November 2009 to November 2019. This demonstrates that the number of CUA studies has risen in the last decade. However, the number of studies retrieved in our review reveals that CUA in India is still in the embryonic stage. One hundred ninety six economic evaluations retrieved in our searches, when compared with the 1249 papers on cost-effectiveness published in the USA between 1979 and 1990 and 1167 papers published between 1991 and 1996 confirm this observation. ${ }^{[6]}$

Several factors explain this difference in number of health economic evaluation evidence in India and in countries such as the UK. In countries such as the UK and Australia, health economic evaluation is mandatory for most of the new drugs and devices coming to the market. There is no such requirement in India. Another reason for smaller number of economic evaluations could be the lack of professional expertise and specialty courses in the domain of health economics.

There are very limited programs and universities which offer health economics as a specialization. As the number of corporates increase in the space of health economics, we anticipate this to have spillover effects on academia. We believe that the introduction of health economics courses at the graduate and post-graduate levels would be beneficial to promote the development of health economics domain in India.

To the best of our knowledge, this is the first paper synthesizing the evidence on CUA studies in the Indian context. The researchers of this study came from diverse disciplines (pharmacy, economics, and public health) which allowed a comprehensive and independent opinion of the review. Government or pharmaceutical company reports and unpublished research might have been missed. Publication bias could have been introduced in the review due to the inclusion of only published studies. Some CUA studies that included India in their analysis could have been missed as we excluded studies that did not report separate data for India. The variation in study designs, therapeutic area, and the state where the study was conducted leads to heterogeneity among studies and thus limited the comparability of the studies. Finally, a minor limitation of the CHEERS checklist can introduce the possibility of bias. As noted by Gerkens et al. ${ }^{[44]}$ the results of the quality assessment of economic evaluation are impacted much more by the assessor than the instrument itself. The mean score of all the 35 studies was 19.21 out of 24 . The quality of CUA studies can be improved by educating and including training by conducting workshops for health-care professionals.

\section{CONCLUSIONS}

Through this systematic literature review, we identified the published CUA studies in India. The overall quality of the included studies was good; however, features such as subgroup analyses and explicit study perspective were missing in several evaluations. There is a need for continued education and training for healthcare professionals in India for generation and reporting of high-quality cost-utility evidence

Financial support and sponsorship

Nil.

Conflicts of interest

There are no conflicts of interest.

\section{REFERENCES}

1. NICE. National Institute for Health and Clinical Excellence. Available from: https://www.nice.org.uk/. [Last accessed on 2020 Mar 16].

2. PBAC. Pharmaceutical Benefits Advisory Committee. Available from: http://www.pbs.gov.au/info/industry/listing/participants/pbac. [Last accessed on 2020 Mar 16].

3. National Health Authority AB. Ayushman Bharat Pradhan Mantri Jan Arogya Yojana. Available from: https://pmjay.gov.in/ about-pmjay. [Last accessed on 2020 Mar 16].

4. HTAIn. Health Technology Assessment in India. Available from: https://htain.icmr.org.in/. [Last accessed on 2020 Mar 16].

5. Desai PR, Chandwani HS, Rascati KL. Assessing the quality of pharmacoeconomic studies in india: A systematic review. Pharmacoeconomics 2012;30:749-62.

6. Prinja S, Chauhan AS, Angell B, Gupta I, Jan S. A systematic review of the state of economic evaluation for health care in india. Appl Health Econ Health Policy 2015;13:595-613.

7. Husereau D, Drummond M, Petrou S, Carswell C, Moher D, Greenberg D, et al. Consolidated Health Economic Evaluation Reporting Standards (CHEERS) statement. Eur J Health Econ 2013;14:367-72.

8. Angell B, Ali F, Gandhi M, Mathur U, Friedman DS, Jan S, et al. Ready-made and custom-made eyeglasses in india: A cost-effectiveness analysis of a randomised controlled trial. BMJ Open Ophthalmol 2018;3:e000123.

9. Arora M, Harvey LA, Glinsky JV, Chhabra HS, Hossain MS, Arumugam N, et al. Cost-effectiveness analysis of telephone-based support for the management of pressure ulcers in people with spinal cord injury in india and bangladesh. Spinal Cord 2017;55:1071-8.

10. Bahuguna P, Prinja S, Lahariya C, Dhiman RK, Kumar MP, Sharma V, et al. Cost-effectiveness of therapeutic use of safety-engineered syringes in healthcare facilities in india. Appl Health Econ Health Policy 2020;18:393-411. 
11. Bender MA, Kumarasamy N, Mayer KH, Wang B, Walensky RP, Flanigan $\mathrm{T}$, et al. Cost-effectiveness of tenofovir as first-line antiretroviral therapy in India. Clin Infect Dis 2010;50:416-25.

12. Brown HS $3^{\text {rd }}$, Stigler M, Perry C, Dhavan P, Arora M, Reddy KS, et al. The cost-effectiveness of a school-based smoking prevention program in India. Health Promot Int 2013;28:178-86.

13. Buttorff C, Hock RS, Weiss HA, Naik S, Araya R, Kirkwood BR, et al. Economic evaluation of a task-shifting intervention for common mental disorders in India. Bull World Health Organ 2012;90:813-21.

14. Chaillon A, Mehta SR, Hoenigl M, Solomon SS, Vickerman P, Hickman M, et al. Cost-effectiveness and budgetary impact of HCV treatment with direct-acting antivirals in India including the risk of reinfection. PLoS One 2019;14:e0217964.

15. Chauhan AS, Prinja S, Srinivasan R, Rai B, Malliga JS, Jyani G, et al. Cost effectiveness of strategies for cervical cancer prevention in India. PLoS One. 2020;15:e0238291.

16. Chugh Y, Dhiman RK, Premkumar M, Prinja S, Singh Grover G, Bahuguna $\mathrm{P}$, et al. Real-world cost-effectiveness of pan-genotypic sofosbuvir-velpatasvir combination versus genotype dependent directly acting anti-viral drugs for treatment of hepatitis $\mathrm{C}$ patients in the universal coverage scheme of punjab state in India. PLoS One 2019;14:e0221769.

17. Dranitsaris G, Truter I, Lubbe MS, Sriramanakoppa NN, Mendonca VM, Mahagaonkar SB. Improving patient access to cancer drugs in India: Using economic modeling to estimate a more affordable drug cost based on measures of societal value. Int J Technol Assess Health Care 2011;27:23-30.

18. Goel A, Chen Q, Chhatwal J, Aggarwal R. Cost-effectiveness of generic pan-genotypic sofosbuvir/velpatasvir versus genotype-dependent direct-acting antivirals for hepatitis C treatment. J Gastroenterol Hepatol 2018;33:2029-36.

19. Gupta N, Verma RK, Prinja S, Dhiman RK. Cost-effectiveness of Sorafenib for Treatment of Advanced Hepatocellular Carcinoma in India. J Clin Exp Hepatol 2019;9:468-75.

20. Gupta V, Baabbad R, Hammerby E, Nikolajsen A, Shafie AA. An analysis of the cost-effectiveness of switching from biphasic human insulin 30, insulin glargine, or neutral protamine Hagedorn to biphasic insulin aspart 30 in people with type 2 diabetes. J Med Econ 2015;18:263-72.

21. Home P, Baik SH, Gálvez GG, Malek R, Nikolajsen A. An analysis of the cost-effectiveness of starting insulin detemir in insulin-naïve people with type 2 diabetes. J Med Econ 2015;18:230-40.

22. John D, Chatterjee P, Murthy S, Bhat R, Musa BM. Cost effectiveness of decentralised care model for managing MDR-TB in india. Indian J Tuberc 2018;65:208-17.

23. John D, Parikh R. Cost-effectiveness and cost utility of community screening for glaucoma in urban India. Public Health 2017;148:37-48.

24. John D, Parikh R. Cost-effectiveness of community screening for glaucoma in rural India: A decision analytical model. Public Health 2018;155:142-51.

25. John MJ, Jyani G, Jindal A, Mashon RS, Mathew A, Kakkar S, et al. Cost effectiveness of hematopoietic stem cell transplantation compared with transfusion chelation for treatment of thalassemia major. Biol Blood Marrow Transplant 2018;24:2119-26.

26. Joshi S, Kulkarni V, Gangakhedkar R, Mahajan U, Sharma S, Shirole D, et al. Cost-effectiveness of a repeat HIV test in pregnancy in India. BMJ Open 2015;5:e06718.

27. Khan A, Amitava AK, Rizvi SA, Siddiqui Z, Kumari N, Grover S, et al. Cost-effectiveness analysis should continually assess competing health care options especially in high volume environments like cataract surgery. Indian J Ophthalmol 2015;63:496-500.

28. Le HG, Ehrlich JR, Venkatesh R, Srinivasan A, Kolli A, Haripriya A, et al. A sustainable model for delivering high-quality, efficient cataract surgery in southern India. Health Aff (Millwood) 2016;35:1783-90.

29. Maddali MV, Dowdy DW, Gupta A, Shah M. Economic and epidemiological impact of early antiretroviral therapy initiation in India. J Int AIDS Soc 2015;18:20217.

30. Mateti UV, Nagappa AN, Attur RP, Nagaraju SP, Rangaswamy D. Cost-effectiveness of pharmaceutical care on patients undergoing maintenance hemodialysis - A multicenter randomized controlled study. Postgrad Med 2018;130:621-6.

31. Mishra SB, Poddar B, Kasimahanti R, Azim A, Singh RK, Gurjar M, et al. Quality of life after intensive care unit discharge in a tertiary care hospital in India: Cost effectiveness analyis. Indian J Crit Care Med 2019;23:122-6.

32. Nadkarni A, Weiss HA, Weobong B, McDaid D, Singla DR, Park AL, et al. Sustained effectiveness and cost-effectiveness of counselling for alcohol problems, a brief psychological treatment for harmful drinking in men, delivered by lay counsellors in primary care: 12-month follow-up of a randomised controlled trial. PLoS Med 2017;14:e1002386.

33. Nadkarni A, Weobong B, Weiss HA, McCambridge J, Bhat B, Katti B, et al. Counselling for alcohol problems (CAP), a lay counsellor-delivered brief psychological treatment for harmful drinking in men, in primary care in India: A randomised controlled trial. Lancet 2017;389:186-95.

34. Prinja S, Bahuguna P, Faujdar DS, Jyani G, Srinivasan R, Ghoshal S, et al. Cost-effectiveness of human papillomavirus vaccination for adolescent girls in Punjab State: Implications for india's universal immunization program. Cancer 2017;123:3253-60.

35. Prinja S, Kaur G, Malhotra P, Jyani G, Ramachandran R, Bahuguna P, et al. Cost-effectiveness of autologous stem cell treatment as compared to conventional chemotherapy for treatment of multiple myeloma in India. Indian J Hematol Blood Transfus 2017;33:31-40.

36. Rachapelle S, Legood R, Alavi Y, Lindfield R, Sharma T, Kuper H, et al. The cost-utility of telemedicine to screen for diabetic retinopathy in India. Ophthalmology 2013;120:566-73.

37. Rosenthal VD, Udwadia FE, Kumar S, Poojary A, Sankar R, Orellano PW, et al. Clinical impact and cost-effectiveness of split-septum and single-use prefilled flushing device vs 3-way stopcock on central line-associated bloodstream infection rates in India: A randomized clinical trial conducted by the international nosocomial infection control consortium (INICC). Am J Infect Control 2015;43:1040-5.

38. Schulman-Marcus J, Prabhakaran D, Gaziano TA. Pre-hospital ECG for acute coronary syndrome in urban India: A cost-effectiveness analysis. BMC Cardiovasc Disord 2010;10:13.

39. Shafie AA, Gupta V, Baabbad R, Hammerby E, Home P. An analysis of the short- and long-term cost-effectiveness of starting biphasic insulin aspart 30 in insulin-naïve people with poorly controlled type 2 diabetes. Diabetes Res Clin Pract 2014;106:319-27.

40. Suen SC, Bendavid E, Goldhaber-Fiebert JD. Cost-effectiveness of improvements in diagnosis and treatment accessibility for tuberculosis control in India. Int J Tuberc Lung Dis 2015;19:1115-24, i-xv.

41. Thakar S, Rajagopal N, Mani S, Shyam M, Aryan S, Rao AS, et al. Comparison of telemedicine with in-person care for follow-up after elective neurosurgery: Results of a cost-effectiveness analysis of 1200 patients using patient-perceived utility scores. Neurosurg Focus 2018;44:E17-E.

42. Weobong B, Weiss HA, McDaid D, Singla DR, Hollon SD, Nadkarni A, et al. Sustained effectiveness and cost-effectiveness of the healthy activity programme, a brief psychological treatment for depression delivered by lay counsellors in primary care: 12 -month follow-up of a randomised controlled trial. PLoS Med 2017;14:e1002385.

43. Hope SF, Webster J, Trieu K, Pillay A, Ieremia M, Bell C, et al. A systematic review of economic evaluations of population-based sodium reduction interventions. PLoS One 2017;12:e0173600.

44. Gerkens S, Crott R, Cleemput I, Thissen JP, Closon MC, Horsmans Y, et al. Comparison of three instruments assessing the quality of economic evaluations: A practical exercise on economic evaluations of the surgical treatment of obesity. Int J Technol Assess Health Care 2008;24:318-25. 